\title{
Study on Cooperative Learning Organization Strategy in College Oral English Class
}

\author{
Yi Liu \\ School of Foreign Studies \\ Anhui Sanlian University \\ Hefei, China 230601
}

\begin{abstract}
Cooperative learning is an effective way to improve students' oral English ability. Successful colloquial cooperative learning requires teachers to be carefully organized and guided. Through the analysis of the problems in oral English teaching, this paper proposes a series of cooperative learning organizational strategies in oral English classroom. And that collaborative learning is to improve students' spoken English ability of an effective method.
\end{abstract}

Keywords-oral English teaching; cooperative learning; organizational strategy

\section{INTRODUCTION}

As one of the four basic skills of English, the oral English ability of English has been neglected for a long time in English teaching. On the one hand, this is due to the problems in the teaching objectives and the setting of the focus, on the other, the situation of the country - the large class teaching has brought a lot of difficulties for the classroom oral teaching. In recent years, the listening and speaking ability of English has been paid more and more attention. Oral English teaching has received more and more attention in college English classroom teaching. How to overcome various difficulties and obstacles and organize effective oral English teaching is still worth exploring for English teachers. And practice of a proposition.

Cooperative learning model is a group-based, learnercentered organization of teaching activities, a teaching model and method (Dillenbourg, 1999). This model emphasizes the learner's self-direction, personal development, personality and intrinsic motivation and sense of cooperation. Therefore, to take cooperative learning mode, to group students as a unit to organize classroom activities, can be achieved so that teachers and students are more satisfied with the results. However, whether or not the desired effect can be achieved in cooperative colloquial classroom activities depends on the implementation of factors such as the planning, organizing, guiding and supervising of classroom activities. Otherwise, it will remain in the simple form of cooperation Learning and can not achieve good results. This paper discusses how to organize effective cooperative learning activities in oral

Fund Project: This paper is the research result that focused on professional comprehensive reform pilot of quality project of Anhui Provincial Education Department "English" (Item Number: 2013zy086) and the key project of humanities of Anhui Sanlian University "An empirical study on the theory of spoken english discourse analysis based on multi modal theory" (Item Number: skzd2016004).
English classroom, and makes a systematic analysis and summarization.

\section{COOPERATIVE LEARNING THEORY AND THE ADAPTABILITY OF COLLEGE ORAL ENGLISH TEACHING}

Since the emergence of cooperative learning theory, scholars have been positive about applying cooperative learning to language classroom. The famous cooperative learning theory research expert Lang and Porter summarized the benefits of cooperative learning as three points: the learners get more opportunities to use the language, the learners use the target language to improve the quality of the learners' individual differences get a considerable degree of care In addition to the general characteristics of spoken English teaching, the teaching of college spoken English in China has its own complexity, such as a series of problems caused by large-scale teaching, such as a large number of students, It is gratifying that the theory and research show that the theory of cooperative learning can better solve the practical problems of college English oral teaching.

Most scholars believe that language teaching more than 40 classes should be considered large classes, is not conducive to the conduct of language teaching, greatly affect the teaching effect. In our university more than 50 large class phenomenon is quite common, and many schools are using the class collective teaching methods, students feel the lack of opportunity to practice oral English. Through the collaborative learning model, the class is divided into several groups with common mission objectives to promote and cultivate positive interaction between students and make full use of students' different interests, learning experiences and different understanding of things and views, to simulate the small class of class Mode, so that students directly participate in classroom learning time to reach the maximum. But also greatly enhanced their interest in learning and interaction between students, resulting in a large number of comprehensible input and output. Learners interact with each other through the process of learning to imitate the ability of better peer reasoning, thinking strategies and problemsolving methods to achieve the internalization of knowledge, ability and skills to promote cognitive development. The same group of students collaborate and help each other, will correct each other bad vocabulary pronunciation. In the same group of partners vocabulary is not enough to express 
difficulties, often to the group within the timely help. Cooperative foreign language learning has become an effective model, because it largely eliminates the learners "self-esteem" too strong psychological barriers to enable them to discuss and discuss issues in a small range in order to reduce the learners in particular Is the psychological pressure of those with learning difficulties, so that they dare to speak. At the same time, cooperative learning helps students get rid of the psychological pressure caused by the fear of individual failure in the competition. The teachers and peers understand comprehensively and make the students in a relaxed and safe learning environment, effectively reducing foreign language learning anxiety opportunity. When the students make efforts for the group to be peer encouragement and positive feedback, can enhance students' self-confidence, so that students see their progress, students are motivated because of progress, resulting in a stronger motivation to learn.

Problem - guided. Teachers can focus on the unit and the difficulties raised a series of related issues, the purpose is to explore the spirit of inspiring students' interest in learning, so that students on a certain topic have a certain depth and breadth of understanding. In addition, problem-based instruction helps students develop critical thinking skills and leads students to self-search for solutions to problems. In this link, it is worth noting that teachers need to mention some open-ended questions, so that students expressed their views on a point of view and unique views. Such as "New Horizon College English Audio-Visual Tutorial" (hereinafter referred to as "audio-visual tutorial") Volume II, the first unit of the question: What kind of music do you prefer, classic music or pop music? Music characteristics and manifestations of further questions, to stimulate students to this knowledge point of thinking, and allow students to comprehensive application of analysis, comparison, judgment and reasoning ability to find the answer to the question. In this process, teachers should pay more attention to provide positive feedback, give students a balanced opportunity to answer, and strive to create an orderly, relaxed, interesting classroom atmosphere, the elimination of student anxiety and anxiety, so that they actively participate in Classroom activities.

Role-playing is a traditional teaching activity in the oral English classroom. Role-playing in the textbook is based on speaking out. And speaking out and has three different modules, each module is the title of the oral practice the most representative sentence. Students asked to first dictate the contents of the module, and then listen to the teacher in the module involved in the key words to explain, and finally in accordance with the scene role-playing. Although the composition of teaching materials on the more level, but this role-playing is just finished listening to the contents of the simple module to imitate, and some even need only replace some of the noun to complete. This is not challenging for students with a medium level of spoken English. Therefore, in order to break this fixed pattern, the first strategy is that teachers can try to reverse the order of teaching. Teachers can first specify the oral English class topic, and the topic set in a scene, arranged for students through group discussions and plays to complete, without prior organization of students to learn the topic of the textbook content, that is, skip the Teaching materials in the first and second links. In this way, students in the process of completing the task had to take the initiative to think, find information, organization of language, expression of ideas, to maximize the mobilization of learning initiative and autonomy. After the student's role-playing, the teacher can immediately point out the language mistake that the student makes and the loophole of idea. This completes the usual sense of asking questions, analyzing problems, and solving problems. In this process, students need to use the analysis, synthesis, reasoning, innovation and other aspects of the ability to maximize the active thinking power, and the teacher's own creative thinking is not a small challenge. At the end of the lesson, the instructor returns to the first and second sessions to play the audio, which allows the student to listen to the original English by listening to the specific action and to compare it with the dialogues he or she prepares. The key words. Different from the traditional practice, students have learned through self-learning, understand the theme, mastered the key points, and finally just a review consolidation process.

Two strategies is that teachers should allow students to more on a topic, multi-angle play, so that students from thinking to imitate the thinking of innovation to change. Such as environmmental problems this topic allows students to choose a role to play, from the perspective of national government officials, the media point of view, the Environmental Protection Association volunteers point of view, a traveler through time and space perspective, the citizens of developed countries, citizens of developing countries Point of view and children's perspective to share their observation experience, and to propose protective measures. This multi-angle play allows students from different perspectives and different positions to think about this issue, to develop the students' ability to speculate.

\section{ORganizational Strategy AND METHOD OF COOPERATIVE LEARNING}

Since the 1980s, psychologists and educators have made a lot of research and discussion on the effect of cooperative learning, most of them think that cooperative learning is better than individual learning, many teachers began to use cooperative learning in the classroom teaching methods. The effectiveness of the cooperative learning model depends largely on the teacher's organizational strategies and methods of classroom activities. Therefore, in order to achieve the effect of cooperative learning, teachers in the implementation of this learning model must be detailed analysis and planning.

\section{A. Planning the Basic Strategy of Cooperative Learning}

In the planning and implementation of cooperative learning specific plans, you can use the following strategies, namely: clear organizational cooperation team principles, to students to clear how to conduct cooperative learning and evaluation methods to help students to train the basic skills of cooperative learning.

- In developing a teaching plan for cooperative learning, it is important to consider the principle of organizing 
the cooperative team, which can be divided into groups by students themselves and spontaneously, or by teachers according to their grades and gender. The question must be considered is how to help the various cooperation groups to communicate internally and to give feedback to each team on a regular basis.

- Students should be explained the implementation of collaborative learning methods and evaluation methods. In the arrangement of any kind of oral activities before the task, students need to clear the purpose and related concepts. Teachers should pay attention to master a set of more objective criteria for the performance of the cooperative team to score.

- The basic skills of cooperative learning should be trained. Many students do not start with collaborative learning experience, do not know how to communicate with other members of the group cooperation. Therefore, the teacher should give students in advance to teach some basic cooperation skills, or training to improve the quality of cooperation. These skills include active listening skills, mutual understanding of language skills, constructive criticism skills, and skills to resolve disagreements.

\section{B. Design Strategies of Classroom Activities}

The design strategies of classroom activities include: properly design group cooperation tasks, supervise team cooperative learning, master the task components suitable for students' abilities and skills, carry out competitions among groups and evaluate and compare them, give test and summarize.

- Properly designed collaborative tasks refer to the task of assigning spoken language activities to groups that are appropriate for multi-person collaboration rather than individual tasks that can be done by individual students when organizing collaborative colloquial classroom activities. For example, the layout of the dialogue and performance tasks, each student can participate in, and fully enhance the enthusiasm of the students, so that everyone get the opportunity to express practice.

- It is important to have a good grasp of the task components that are appropriate for students' abilities and skills. Too complex and too simple task is not conducive to the cooperative learning group. Overly complex tasks will dampen students' sense of accomplishment, not conducive to the cooperation of the group. Teachers should be designed for students spoken language level, while students are concerned, interested, or practical spoken language tasks.

- Timely assessment and summary. You can choose to do comparative evaluations at the beginning of the semester or at the end of the term, give the test, and make a summary. At the beginning or the end of a learning period, students are tested in groups on a group basis in a timely manner to understand the students' spoken language ability and the effectiveness of team work. Can carry out evaluation tests, quizzes, or layout of homework.

\section{EVALUATION STRATEGY OF COOPERATIVE LEARNING}

The so-called scenario creation through audio and video, simulation performance, reproduction of life, etc. to create an atmosphere in order to allow readers, the audience a better understanding of the works of a teaching method. The English teaching scene creation, is through a series of ways to enable students to learn as a mother tongue to learn foreign languages. The creation of the scene in oral English teaching can play the role of arousing the emotion and igniting the passion and inspiring the students to communicate. The context of oral English teaching refers to the social scene of foreign language communication. Language is the expression of its meaning in the scene, the scene is to reveal the meaning of the language one of the basic elements. People in the use of language communication activities, can not be separated from the social language scene. The creation of scenarios in oral teaching is actually in the reproduction of life, to students to create a living atmosphere, because the students only in the real language scenarios or simulated scenarios to better organize thinking, touch the scene and stimulate the desire to express ideas, So as to promote the use of English and improve the ability to express. Therefore, how to create scenarios is an important part of Oral English teaching design.

Cooperative learning has no perfect scientific evaluation system at home and abroad, so how to evaluate the cooperative learning model of college English oral teaching is also a very important and meaningful question. In the oral practice class, the appropriate evaluation criteria and incentives to guide and regulate the students' learning process plays an important role. There is no doubt that the teacher wants to get recognition, praise and appreciation of other students, which is the common psychological characteristics of each student. Reasonable evaluation of their achievements can be encouraged by the students, resulting in a huge learning motivation.

Oral English cooperative learning is a kind of basic organizational form, in which group members help each other, so as to promote their own and others' oral learning to the maximum extent and achieve common learning goals. Teachers in the design of colloquial cooperative learning classroom activities, students should fully consider the individual factors, through the use of cooperative learning, so that students in the analysis and problem-solving ability and language communication skills to further improve, so that students with confidence, Complete their learning tasks. (A) give full play to the leading role of teachers A new era of English teaching requirements to teachers has brought unprecedented challenges, it requires English teachers need to have profound professional knowledge, but also need to have the ability to introduce new ideas, can freely manage textbooks and classroom Teaching process, flexible organization of classroom teaching activities. First, break through the traditional teaching mode, explore the creative spoken language cooperative teaching. To carry out creative 
teaching requires teachers to quickly update the concept of education, give full play to the leading role of teachers to guide students to identify problems and solve problems. Teachers should be in the colloquial cooperative learning as a manager, organize students to group activities; as a monitor to master the process of activities; as information providers, to provide independent activities for students to provide materials and guidance; as a tutor to correct student errors; To help students rational control of their original cognitive system. At the same time, the teacher is also the designer and guide of classroom activities, but also the student problem analysis and solution. Through the creation of cooperative activities conducive to the selection of classroom activities to guide students to solve problems through group work to fully tap the potential of students to learn, to cultivate the spirit of cooperation and a serious and positive attitude towards learning.

The significance of cultivating students' thinking ability in college oral English class. The cultivation of speculative ability is conducive to injecting new vitality and discerning ability into college English oral class. This has changed the traditional teaching mode and brought a qualitative leap to college oral English class. It is precisely because of the intervention of this element of speculative ability that College English Oral Class really plays a role in helping students master the language knowledge to the practical application of language. The cultivation of speculative ability is conducive to active classroom atmosphere, and enhance the enthusiasm of students to learn English thinking ability to fully mobilize the oral classroom students in the participation. In each teaching activity, the student is the teaching subject, is the teaching front-line participant. Student knowledge is not only derived from the guidance and comments of teachers, but also more students from each other between the discussion and a separate demonstration of students. Therefore, the College English oral classroom is no longer boring, no longer only imitation and practice sound, but on a point of view is full of different views of the exchange of voice and discussion. The cultivation of speculative ability is conducive to stimulate the innovation ability and selflearning ability of university students. The thinking ability and innovative thinking are mutual basis and complement each other, and the thinking ability provides a space for the development of autonomous learning ability. These three are the main impetus for advancing the knowledge society in the future. The cultivation of speculative ability is conducive to the effective teaching of teachers reflective thinking ability to help students to teachers to make a correct evaluation of teaching, the teacher is through the feedback of students in time to adjust the appropriate teaching mode, the necessary reflection of teaching activity.

Through the teacher assigns the spoken language reasonable task and the attention language factor input, changes the tradition by the teacher "the unification classroom" the situation, establishes the atmosphere and the condition for the student to study independently, forms the interaction with the student. Second, create a relaxed, harmonious, positive classroom atmosphere, the establishment of a harmonious relationship between teachers and students. The guidance of cooperative learning should respect the development of students' personality and personality and establish the sense of equality. It depends on whether there is a relaxed, harmonious and positive teaching environment. Students who feel anxious about oral English learning often do not take the initiative to speak or actively participate in classroom communication because they are afraid of making mistakes and afraid of making mistakes. Therefore, the scientific treatment of language errors in the classroom, teachers create a relaxed and happy learning environment key. Students should be tolerant of language errors, teachers should not be wrong immediately corrected, students should understand that the error is not a symbol of failure, but the process of learning English is a normal phenomenon, is an opportunity to learn, and thus So that students be encouraged.

Formative assessment of teaching is a kind of teaching process through the timely and effective feedback to promote the healthy development of language teaching evaluation.Compared with the end of assessment, formative assessment can better reflect the following characteristics: First, teachers can effectively grasp the students The third is to facilitate students to understand their learning situation, improve learning methods, improve learning efficiency.The third feature is particularly important in college oral English classes.Teachers can be a teacher, teacher can be a real teacher, The use of flexible assessment tools, such as oral reports, role play, scene repetition, phonetic intonation test, oral contest, speech contest, all-round, time-tested student learning effect.Meanwhile, it should be noted that the formative assessment But also the self-assessment of students and the assessment between students.So, in this process, students are not passive, but the initiative.Student based on the assessment results in real time to adjust their learning and learning strategies, and on Students to actively reflect on the whole process of teaching, constantly asked myself: I still have any shortcomings in spoken English, what other people have a good place to learn from? What needs to be done in terms of logical cohesion, verbal intonation, or on-the-spot ability? How to improve? What are the ways to improve? This series of questions is bound to motivate the student's ability to speculate to a great extent.

Constructivism argues that learning is the active construction of students, learning should be linked with a certain situation, in the actual situation to learn, so that students can use the original knowledge and experience to assimilate the current learning new knowledge. Professor Yang Huizhong, a Chinese language expert and professor at Shanghai Jiaotong University, said, "Language communicative competence testing must be conducted in a real-world context using real language materials. Students are expected to use language in the real context to achieve communicative goals. "In people's daily communication, the information difference (Informationgap) is the people to communicate and communicate directly. The use of language communication is to carry out the exchange of information to fill the gap between the two sides of communication information. Therefore, when we strive to enable students to use the language for real communication 
and communication, we can target the language project in the scene to create a certain amount of information poor activities to stimulate students to fill the information poor desire to guide students to use the relevant language project Information exchange. In the design of communicative exercises, only the creation of a poor information context, students will have communication between the needs and aspirations, will be willing to speak, communicate in English, to use the language of the purpose of learning. In the teaching, some teachers in the organization of communication practice, pick up the book and asked: "What's this?" Students answer: "It'sabook." This communication is "know-how" question and answer, no information difference between the two sides is a false communication. This "know-how" exercise, if the practice of language links is possible, because the main purpose of practice language is to enable students to master the pronunciation, intonation and sentence structure. But the use of language in the communication link is still "knowingly" exercise, it lost the effectiveness of the use of communication. There are many ways to create oral communication, but the most basic requirement is to be close to life. Only the situation from life is in line with the characteristics of students and ideological reality. The creation of teaching situations need to make full use of students' living resources, so that teaching close to the students, close to life. Therefore, in the teaching of oral communication, teachers in addition to those "example" "training theme", the students must also be around the things around, good at capturing and discovering similar situations in life, as close as possible to create life Context, for oral communication training. Only in this way can stimulate students desire to stimulate the full participation of students willing to participate in practical and improve oral communication skills.

\section{A. The Principle of Wholeness}

As the use of teaching in the form of groups, it is not appropriate in the evaluation of the main individual students as the basic unit, but should be mainly in groups as the basic unit. Congratula-tions to all of you!", "This group really did a good job and all the members are excellent." The language of a group of evaluation groups is more appropriate, this evaluation team as a whole is conducive to further develop the spirit of unity and cooperation of students and collective sense of honor. Regardless of the group form or learning content, should also pay attention to the evaluation of care, for all members of the group, excellent poor students should take into account, should avoid the group eugenics arranged this phenomenon, or poor students In-group learning will be passive and negative. The process of oral communication is a process of interaction between listening and speaking, which is carried out in a specific communicative context. Oral English teaching is mainly to allow students to say more practice. But let the students repeatedly monotonous practice, will become boring, learning efficiency. In the English teaching by adding appropriate scene creation, the more difficult to memorize the language project in the relaxed and lively activities to be able to grasp, through a variety of scenarios, contact life reality, on the one hand active classroom atmosphere, memory knowledge; To avoid a result of boring to follow the tired and boring. It has been suggested that "no situation without teaching", in fact, the situation is teaching.

\section{B. The Principle of Openness}

Openness is in the evaluation of open evaluation of personnel, time, space, let the group learn this basic form is more energetic, live. First of all, open from the staff, completely changed the phenomenon of teachers a speech hall, and more to take the group self-assessment, other groups of his assessment of the form, everyone involved in the evaluation of the interactive situation. When the group members can not complete the task in time, may be allowed to ask a group of free, and still by their reporting, communication, speaking, which is conducive to the establishment of mutual relations between the group and the group to better form the class group. Oral English classes require a high level of language, which requires teachers to be fluent in their spoken language, which is better than verbal instruction and teachers.

A large extent determine the efficiency of the students in the classroom mental work, that is to say, the level of teaching language teaching directly restricts the level of teaching efficiency.More importantly, the teacher should have easy to skillfully use the language to guide students into the situation Ability. Teachers on the one hand to create a good communication environment for students, on the one hand to pay attention to reflect the characteristics of two-way interaction. The role of teachers is to create context, to help guide, inspire positive thinking. The setting of the teaching situation is a dynamic process, which permeates the train of thought and idea of the teacher, not the template. Scenes contain not only scenes, but also emotions. Any classroom teaching situation without the emotional input of teachers will lose its teaching function. Oral English class, there are many English scene design, teachers should rational use of resources, combined with teaching materials for students to design a life of relevance, real and lively communication scenarios. Only in this way can the students unwittingly speak English. Teachers in the process of setting up the scene should adhere to the "student autonomy, open environment, focus on practice, to encourage innovation", through situational teaching, the boring and lively, a single repeat for the fun, flexible application in order to complete The most convenient, the most economical, the most infinite charm, is still the teacher's language, facial expressions and body language.Therefore, the teaching environment.

\section{StRategies AND Methods OF COLLEGE ENGLish ORAL CLASSROOM TEACHING BASED ON APPLICATION PRINCIPLE}

\section{A. On the Application of Oral English Teaching in College English}

Positive Changes in College Oral English Teaching Ideas: An Important Measure to Improve the Effect of College Oral English Teaching. First of all, teachers should actively change the teaching philosophy, to pay attention to the 
practical and application of oral English teaching, to develop students' practical ability of spoken English as the main goal of oral English teaching, as a fundamental concept of college English oral teaching Methods. Secondly, students should actively change the concept of participation in oral English learning, to recognize the oral English teaching on their overall quality of energy improve the importance of the role, and actively participate in the oral English teaching process, consciously in the practical application to improve their oral English ability. In addition, according to the scientific concept of oral English teaching, setting the teaching objectives of oral English, in order to achieve the effectiveness of teaching objectives, teachers should analyze the contents of oral teaching materials and students 'actual situation, understand students' knowledge of oral English Reserves and capacity levels, to ensure that the development of educational goals and students will not be a big gap between. According to the teaching requirements of each colloquial class and the actual situation of the students, we should set the goal of the level teaching. Through the setting of the level goal, we should study the students' oral English learning interest and self-confidence to cultivate.

\section{B. Reforming College Oral English Teaching Methods}

The innovation of teaching method is the important content of the reform of application - oriented college English classroom teaching. First of all, teachers should combine the actual life of college students and the actual development of the times, choose to meet the students interest in spoken language learning topics, oral English topics, the choice can be related to the students and students, but also can be related to the actual life of students, in short, the choice of oral practice topics to be able to stimulate students interest in learning so that students can find the content of oral practice, Can say ". Secondly, teachers should innovate the teaching mode of spoken English, create oral teaching scenarios, and organize oral practice through scenarios. In the oral teaching process interspersed with game design enrich the spoken language classroom organization, so that the spoken language training mode is more rich and colorful. In addition, you can also English movies, English songs and other forms of teaching materials into the oral process of the classroom, to the movie clips dubbing, organizing English song competition, to carry out simple English debate, etc., through a variety of ways to students of the spoken language ability to carry out training. Finally, in the course of college English oral teaching, we can make full use of modern multimedia and network teaching methods, enrich the materials and means of oral practice, and carry out the teaching of spoken English in applied university. The network can provide rich teaching content for oral English teaching., Spoken language teaching content is also very diverse forms of expression, video, audio, pictures and so can become a stimulating interest in the content of teaching materials, is conducive to improving the level of oral English teaching.

\section{Strengthen the Confidence of Students to Participate in Oral Practice}

Whether students have self-confidence in oral English learning is related to the application of college English oral teaching the key. In the process of oral English teaching, teachers should adopt methods to train students' oral selfconfidence. First of all, teachers should create more opportunities for students to practice speaking, so that students can more open, more practice. Second, teachers should help students to overcome the psychological barriers to learning spoken English, by encouraging and motivating students to find their own self-confidence in oral English learning, voice, tone of praise to the students, the poor pronunciation, tone is not allowed Students to give guidance and encouragement to help these students develop good oral pronunciation habits. In short, to strengthen students' confidence in learning English is to create more students speak English, and the students in the process of speaking practice to encourage and praise, fully affirmed the students in oral and oral learning process performance, Students can not blindly blame the mistakes in oral practice, with the students to find where mistakes exist, patience to guide students to improve and improve oral English teaching strategies to enhance and enhance students' confidence in oral English learning.

\section{Constructing Good Oral English Teaching Environment}

To create a good atmosphere of oral teaching to better enable students to appreciate the importance of spoken language learning, recognizing the specific application of spoken language in practice. Create a teaching atmosphere mainly from the following aspects to take measures. First of all, to create a relaxed, pleasant atmosphere of oral English classroom teaching, teachers and students to communicate more and strengthen the emotional maintenance of teachers and students to increase students' feelings for oral English learning, emotional transfer to create an easy, A pleasant classroom atmosphere. Second, the university should adopt a variety of measures, such as the development of oral English learning societies, regular oral English contest and the establishment of oral English communication platform. Through various measures to create a good atmosphere of oral English teaching to stimulate students desire to speak English. It should be noted that oral English teaching can also be combined with the future employment environment of students, according to the professional learning situation of students, simulate the situation of employment education, so that students in the simulated environment to practice oral, lay a good foundation for future employment. Teachers also guide students to the community often appear in English consciously learning, in fact, many things are in English, such as roadside advertising slogan, tourist spots in scenic spots, etc., these are college English spoken The important atmosphere of teaching.

\section{E. Strengthening the Oral Proficiency and Teaching Ability of College English Teachers}

In order to improve the teaching effect of spoken English, it is necessary to construct a high-level oral English teaching 
team in order to improve the oral English teaching of applied - oriented college. First of all, the University of English teachers on a regular basis for the organization of oral English seminars and oral English Contest, College English teachers to enhance their ability to improve their oral English, and through these activities in front of students to show the charm of spoken language so that students have a more intense oral English learning interest of. Secondly, teachers should actively participate in social practice to improve their oral English practice ability, and through social practice, to understand the current economic and social development of the spoken English ability requirements, can be in the process of oral English teaching a better combination of actual to carry out targeted, suitable for practical application of oral teaching activities. Teachers' oral English level will have a direct impact on the effectiveness of oral English teaching, colleges and universities should pay attention to the construction of high-level teachers, to provide students with better teaching guidance.

\section{CONCLUSION}

Modern English teaching innovation refers to a lot of people in non-native countries paying more and more attention to the teaching and research issues. In the modern English classroom, "student-centered" teaching philosophy has gradually accepted and they were accepted by the majority of teachers and students in the classroom from passive lecturers, recipients of knowledge into classroom activities, active participants. Cooperative learning allows students to learn the enthusiasm and initiative to fully mobilize, active oral classroom atmosphere, improve the efficiency of spoken language training in the classroom. Based on the study of cooperative learning at home and abroad, this paper has systematically explored teaching practice and put forward a series of classroom organizational strategies for colloquial cooperative learning, and has done a scientific analysis of the spoken English cooperative learning achievement . Practice shows that students are the mainstay of teaching activities, it is important to ensure that the subjective position of language practice and create a lively environment for oral English learning, but teachers must recognize that the control of classroom activities is a successful cooperation Type of learning to protect, to take effective organizational strategy, in order to ensure good oral teaching effect.

\section{REFERENCES}

[1] Brown, H. Douglas. Teaching Principles: An Interactive Approach to Language Pedagogy [M] .New Jer-sey: Prentice Hall Regents, 1994.

[2] Cuseo J. Collaborative \& cooperative learning in higher education: A proposed taxonomy $[\mathrm{J}]$.Coopera-tive Learning and College Teaching, 1992, (2).

[3] Johnson D.W., \& Johnson, R. T. Learning together and alone: cooperative, competitive, and individualistic learning (4th ed.) [M] Boston: Allyn \& Bacon, 1994.

[4] MA Xiao-lan. Experimental Research on the Application of Cooperative Learning in English Writing Teaching [J] .Journal of Sichuan International Studies University, 2006, 22 (3): 137-140.
[5] WANG Xiao-hui.The Problems and Strategies of College Oral English Learning [J] .Chinese Science and Technology Innovation Guide, 2011 (28): 106-107.

[6] Hu Aimei. On Cooperative Learning in College Oral English Teaching [J]. Journal of Shanxi Agricultural University (Social Science Edition), 2009 (8). 